\title{
Pusat Layanan Anak Usia Dini Terpadu Sebagai Tempat Penyelenggaraan Pendidikan Inklusi Dengan Pendekatan Psikologi Arsitektur Di SURAKARTA
}

\author{
Devi Rusdiana P, Hadi Setyawan, Bambang Triratma \\ Program Studi Arsitektur \\ Fakultas Teknik \\ Universitas Sebelas Maret Surakarta \\ Email : devirusdianaputri@gmail.com
}

\begin{abstract}
Planning and designing Children Care and Education Centre in Surakarta, that running out inclusive education, is motivated by the importance of developing the potential of children at early age. But unfortunately, this is not supported by the availability of educational facilities in the early levels, especially those who are able to serve both children with and without disabilities. Inclusive learning method is chosen as the most suitable learning method for both children with and without disabilities. The main issue of this design is how building's elements accommodate both children with and without disabilities and support inclusive environment. The implementation of psychology of architecture's concepts is used to support the growth and development of both children with and without disabilities through internal and external stimulation. Those stimulations are given through activity and architectural element such as room's layout, room's interior, building façade and complementary elements like landscape. Those would support the interaction between both children with and without disabilities in creating inclusive environment that support the learning process and development of every child.
\end{abstract}

Keords : Children with disabilities, Early age, Inclusive education, Interaction, Psychology of architecture.

\section{PENDAHULUAN}

Pendidikan tidak hanya diperuntukkan bagi anak normal saja, namun juga bagi anak berkebutuhan khusus (ABK). Sistem pendidikan anak normal dan anak berkebutuhan khusus berbeda karena kestabilan emosi dan tendensi perilaku ABK yang sulit diprediksi. Pendidikan inklusi merupakan upaya untuk menyelenggarakan sistem pendidikan universal yang mampu meningkatkan peran sekolah dalam memahami dan memenuhi kebutuhan peserta didiknya, khususnya peserta didik dengan kebutuhan khusus (Sunaryo, 2009).

Di Indonesia, sistem pendidikan inklusi belum banyak dimulai pada jenjang usia dini. Seperti yang dilansir oleh Joglosemar pada tanggal 4 Desember 2009, jumlah fasilitas pendidikan anak usia dini di Kota Surakarta yang secara tidak langsung telah menyelenggarakan sistem pendidikan inklusi hanya berjumlah 6 sekolah. Kota Surakarta merupakan salah satu kota percontohan inklusi di Indonesia. Maka diperlukan perencanaan dan perancangan pusat layananan pendidikan anak usia dini yang didukung dengan fasilitas taman penitipan anak (TPA), kelompok bermain (KB), taman kanak-kanak (TK) dan layanan terapi. Guna mewujudkan lingkungan didik yang optimal dalam menunjang tahapan interaksi dan tumbuh kembang peserta didik, konsep Psikologi Arsitektur diterapkan pada pola kegiatan, tata ruang, tata massa dan tata lansekap guna menciptakan rangsangan internal serta rangsangan eksternal bagi peserta didik.

\section{METODE}

Konsep Psikologi Arsitektur yang diterapkan mengacu pada kaidah metode perancangan Psikologi Arsitektur yang terdiri dari aspek visual, proses pengamatan, persepsi yang dituangkan pada tata dan ekspresi ruang, aspek ruang personal yang dituangkan pada pemintakatan kelompok ruang terhadap 
tapak, serta aspek teritorialitas dan proksimitas yang dituangkan pada tata massa. Metode perancangan ini diharapkan mampu menciptakan keterikatan emosional antar peserta didik dalam berinteraksi dan guna menghasilkan desain berbasis Psikologi Arsitektur yang mampu memenuhi nilai fungsi, kreativitas, kebutuhan ruang dan pengguna (Deddy, 2005:56).

\section{ANALISIS}

A. Analisis Pengaruh Psikologi Arsitektur Pengaruh konsep Psikologi Arsitektur terhadap perancangan obyek rancang bangun meliputi beberapa aspek berikut :

1. Pola kegiatan pengguna bangunan Segala rangkaian kegiatan pembelajaran dan pendidikan, diharapkan mampu menstimulasi peserta didik untuk berkembang sesuai dengan usianya dan saling menghargai satu sama lain.

2. Pengelolaan ruang

Keberadaan ruang-ruang pada obyek rancang bangun digunakan sebagai stimulan atau rangsangan bagi proses interaksi dan tumbuh kembang anak melalui ekspresi tampilan ruang, dimensi ruang, skala dan proporsi ruang.

3. Pengelolaan massa

Pengelolaan massa diwujudkan dalam bentuk tata massa yang aksesibel untuk mencegah ketakutan pada anak dalam menciptakan ruang geraknya.

4. Pengelolaan elemen komplementer Elemen lansekap digunakan sebagai media untuk menunjang keberhasilan proses pembelajaran dan pendidikan pada.

B. Analisis Peruangan

1. Pelaku

Pelaku kegiatan terdiri dari:
a. Peserta didik (utama)
b. Pengelola
c. Tenaga medis
d. Orang tua murid

2. Analisis Pola Kegiatan (utama)

Guna menunjang tahapan interaksi antar peserta didik, maka pola kegiatan peserta didik disesuaikan dengan tahapan interaksi yang bersifat dari umum ke khusus (lihat Gambar 1).

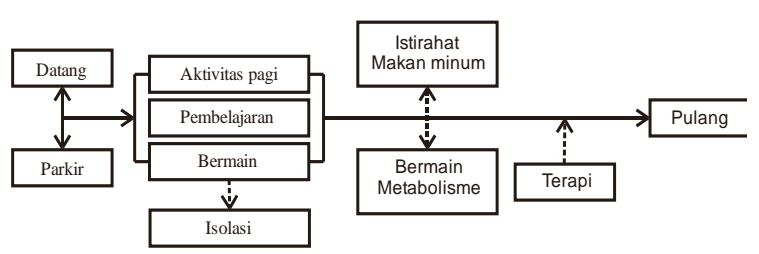

Gambar 1. Pola Kegiatan Peserta Didik

3. Analisis Kebutuhan Ruang Berikut kelompok kebutuhan ruang pada obyek yang direncanakan :
a. Area pendidikan
b. Area pengasuhan
c. Area pengelolaan
d. Area penunjang
e. Area servis

4. Analisis Karakteristik Dimensi Pergerakan Pengguna (utama)

a. Dimensi pergerakan anak nonberkebutuhan khusus (lihat Gambar 2).

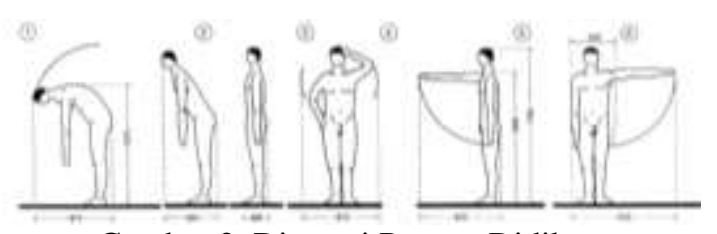

Gambar 2. Dimensi Peserta Didik

Sumber : Architects' Data, Neufert.

b. Dimensi pergerakan anak dengan kursi roda (lihat Gambar 3).
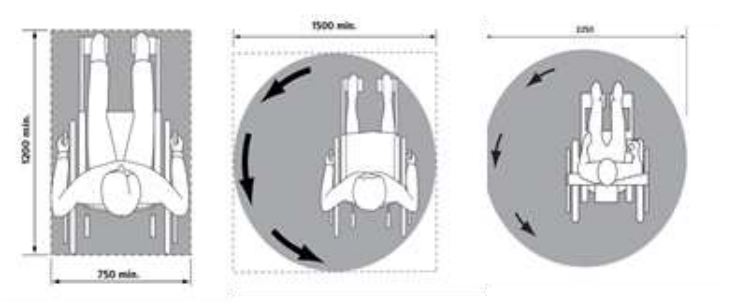

Gambar 3. Dimensi Peserta Didik dengan Kursi Roda

Sumber : Architects' Data, Neufert.

c. Dimensi pergerakan anak dengan kruk (lihat Gambar 4). 

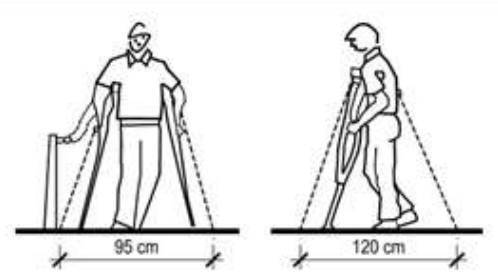

Gambar 4. Dimensi Peserta Didik dengan Kruk Sumber : Architects' Data, Neufert.

5. Analisis Karakteristik Bentuk Ruangruang Khusus

a. Ruang terapi okupasi

Terapi okupasi adalah terapi bagi anak berkebutuhan khusus untuk meningkatkan kemampuan sensorik halus dan kasar (lihat Gambar 5).

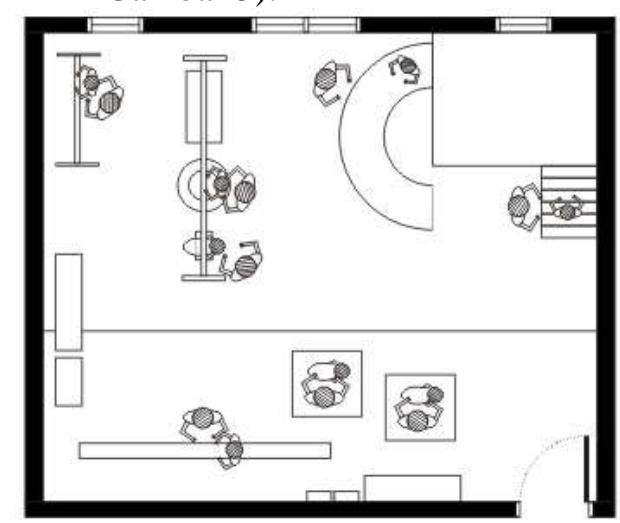

Gambar 5. Ruang Terapi Okupasi

b. Ruang terapi wicara

Terapi ini tidak membutuhkan suatu alat khusus. Kegiatan terapi wicara dilakukan dengan metode one on one agar lebih optimal (lihat Gambar 6).

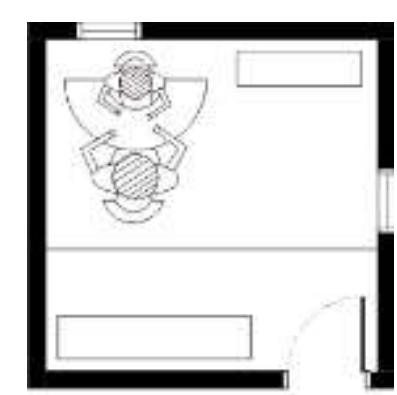

Gambar 6. Ruang Terapi Wicara

c. Ruang terapi audio visual

Merupakan ruangan terapi stimulasi multisensori (visual, auditori, taktil dan pembauan) yang digunakan untuk anak-anak berkebutuhan khusus (lihat Gambar 7).

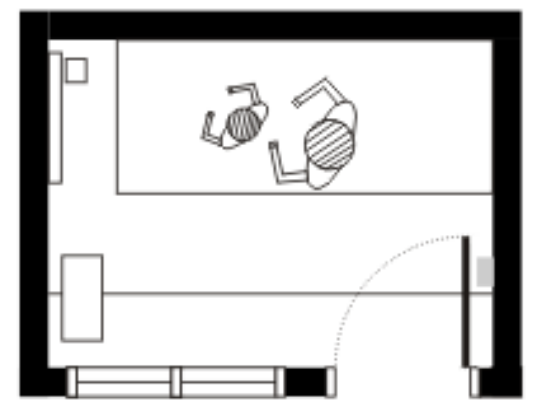

Gambar 7. Ruang Terapi Audio Visual

6. Analisis Pemintakatan Ruang Terdapat dua macam pemintakatan ruang pada tapak obyek bangunan yang direncanakan, yaitu :

a. Pemintakatan berdasarkan sifat kelompok ruang pengguna seperti publik, semi-publik, privat dan servis (lihat Gambar 8).
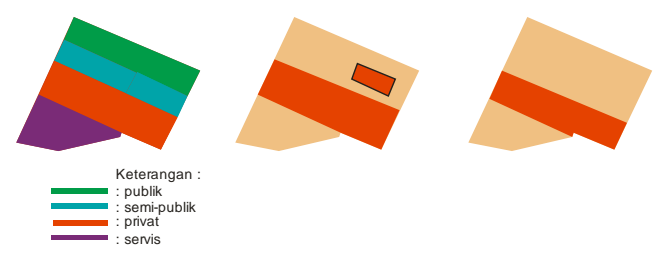

Gambar 8. Pengelompokkan Fungsi Ruang terhadap Tapak

b. Pemintakatan berdasarkan fungsi ruang terhadap tahapan interaksi seperti pra-interaksi, interaksi dan pasca-interaksi (lihat Gambar 9).

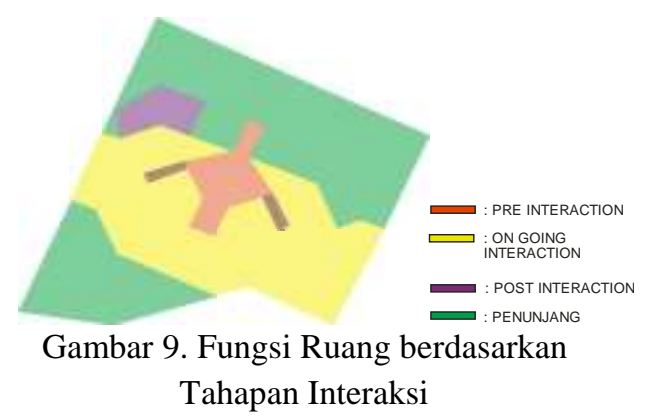

7. Analisis Konsep Elemen Interior Bangunan

Tujuan :

Mendapatkan konsep interior bangunan yang mampu menstimulasi anak. 
Dasar pertimbangan :

a. Sesuai dengan pelaku dan kegiatan yang akan diwadahi

b. Sesuai dengan fungsi ruang

Hasil :

a. Langit-langit

Menggunakan material gypsum board dengan bentuk desain langit-langit seperti flat, up dan drop ceiling.

b. Elemen dinding

Menggunakan material yang mudah perawatannya, tidak mengandung zat berbahaya dan aman.

c. Elemen lantai

Menggunakan material dengan permukaan halus dan rata seperti parquet, karpet dan vynil.

d. Aspek dekorasi dan warna

Elemen dekorasi yang dipilih adalah aplikasi bentuk huruf, angka serta bentuk-bentuk dasar geometris. Sedangkan warna primer diaplikasikan pada area lobby dan selasar koridor ruang. Warna cerah atau terang digunakan pada ruang dengan tingkat kegiatan tinggi seperti ruang bermain. Warna netral digunakan pada ruang-ruang dengan suasana tenang seperti ruang kelas, ruang kesehatan, ruang terapi, ruang tidur, perpustakaan dan kantor pelayanan.

e. Aspek perabot dan antropometri pengguna

Menggunakan perabot yang ergonomis dan aman bagi peserta didik.

f. Keamanan

Menunjang keamanan peserta didik, seperti dinding yang tidak bersudut, dinding ruang yang dilapisi busa (ruang-ruang tertentu), tepian melengkung pada perabot yang digunakan oleh peserta didik, bukaan jendela mengarah ke atas agar peserta didik tidak mudah terbentur dan sulit menjangkau jendela, ramp dengan kemiringan $7^{\circ}$ yang aman, tidak licin dan dilengkapi dengan handrail serta penggunaan guiding block sebagai arah panduan berjalan bagi anak berkebutuhan khusus.

C. Analisis Penataan Tapak

1. Analisis Tapak

Tujuan :

Mendapatkan lokasi tapak yang sesuai dengan kriteria tapak obyek rancang bangun

Dasar pertimbangan :

a. Fasilitas pendidikan berada pada area yang sudah di tentukan kegunaannya sebagai area pendidikan atau pada tempattempat lain yang mendukung, seperti area pemukiman

b. Tapak mampu menciptakan ruang-ruang dan lingkungan pendidikan yang kondusif dan optimal

c. Kontur tanah relatif datar

d. Tapak berada pada area yang aman dan mudah dicapai

e. Berada di Kota Surakarta, karena Kota Surakarta merupakan kota percontohan inklusi sejak tahun 2013

\section{Hasil :}

Lokasi tapak terpilih berada di Jalan Kutai Raya, Sumber, Banjarsari, Surakarta. Lokasinya terletak \pm 180 $m$ dari Jalan Letjend Soeprapto. Tapak merupakan area lahan kosong yang berada di area pemukiman (lihat Gambar 10).

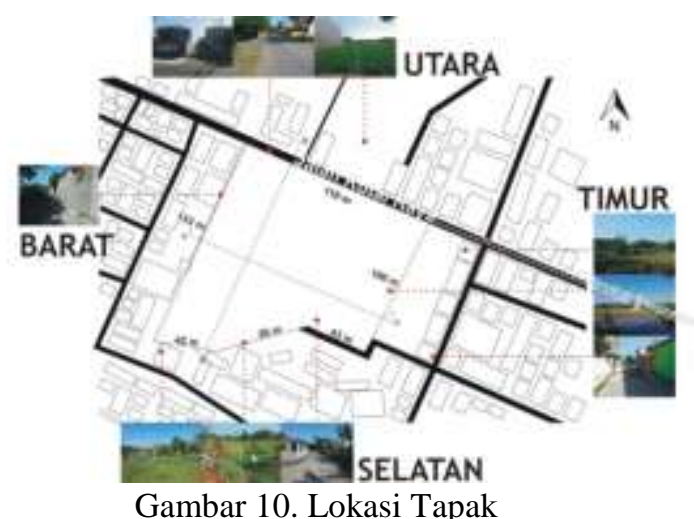

2. Analisis Pola Pencapaian

Tujuan :

Menentukan pola pencapaian menuju tapak yang direncanakan.

Dasar pertimbangan : 
a. Keberadaan fasilitas perlu ditunjang dengan aksesibilitas yang mudah, yaitu pencapaian yang jelas, mudah dan terarah dengan baik

b. Menunjang kenyamanan pengguna

c. Intensitas kendaraan dan jenis kendaraan

d. Kondisi di sekitar tapak

Hasil :

Letak main entrance (ME) in/out berada di Jalan Kutai Raya dan digunakan untuk sirkulasi kendaraan pengelola dan pengunjung. Sedangkan letak side entrance (SE) berada di arah timur laut dan tenggara, digunakan untuk mengakomodasi kegiatan penunjang dan servis (lihat Gambar 11).

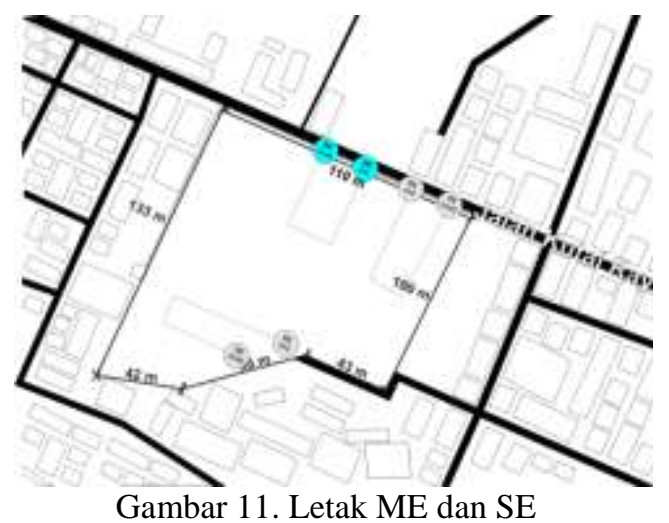

3. Analisis View dan Orientasi

Tujuan :

Menentukan orientasi tapak guna menunjang kemudahan visibilitas massa bangunan utama secara tepat dan menguntungkan.

Dasar pertimbangan :

a. Arah orientasi tapak yang menunjang kemudahan akses oleh pengguna

b. Kondisi di sekitar tapak terpilih dilihat dari keberadaan/letak jalan utama

Hasil :

Agar bangunan lebih mudah diketahui keberadaannya dan dijangkau, maka orientasi bangunan mengarah ke arah timur laut atau ke arah Jalan Kutai Raya (lihat Gambar 12). Orientasi obyek bangunan yang direncanakan dari dan pada tapak nantinya dapat digunakan untuk memetakan gradasi ketinggian dan letak massa bangunan yang disesuaikan dengan tahapan interaksi pada peserta didik (lihat Gambar 13).
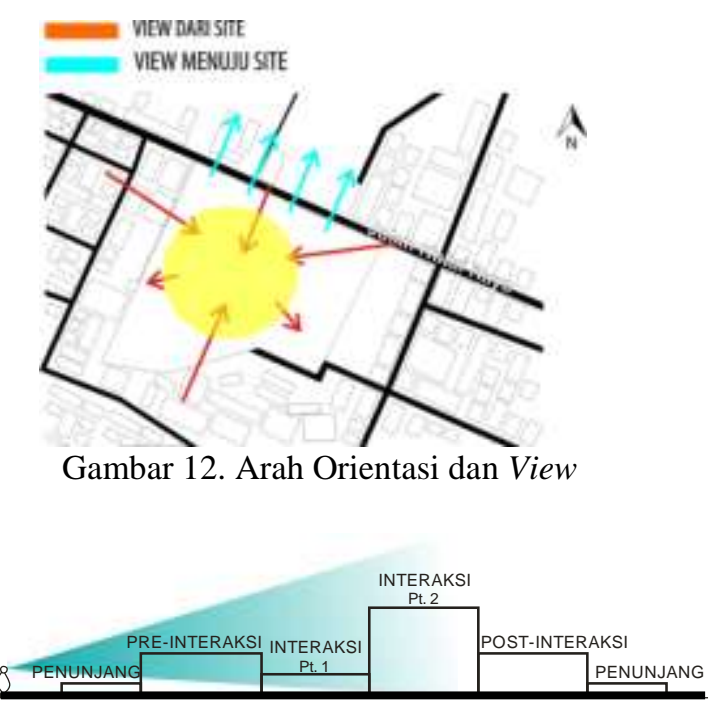

Gambar 13. Gradasi Ketinggian Massa

D. Analisis Bentuk dan Tatanan

1. Analisis Bentuk Bangunan

Tujuan :

Memperoleh bentuk bangunan yang sesuai dengan fungsi bangunan Pusat Pelayanan Anak Usia Dini di Surakarta.

Dasar pertimbangan :

a. Sasaran pengguna

b. Tidak mengurangi kualitas bangunan sekitar

c. Bentuk bangunan sebagai representasi tujuan dan fungsi bangunan

Hasil :

Bentuk dasar terpilih adalah bentuk persegi dikarenakan bentuknya yang stabil, mudah di transformasikan menjadi bentuk lain, mudah dipetakan secara visual, sederhana dan mudah dipahami. Selain itu, bentuk ini adalah bentuk yang paling komunikatif untuk mengintepretasikan tahapan interaksi yang terbagi menjadi pra-interaksi, interaksi dan pasca-interaksi pada peserta didik (lihat Gambar 14). 


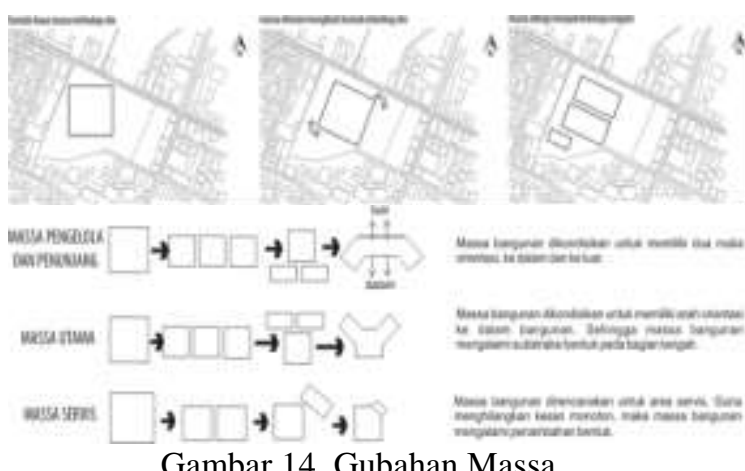

Gambar 14. Gubahan Massa

2. Analisis Tata Massa Bangunan

Tujuan :

Memperoleh konsep layout bangunan yang sesuai dengan fungsi dan jenis kegiatan yang akan diwadahi pada Pusat Pelayanan Anak Usia Dini di Surakarta.

Dasar pertimbangan :
a. Pola kegiatan
b. Fasilitas penunjang
c. Keadaan eksisting tapak
d. Orientasi bangunan
e. Kenyamanan pengguna
f. Ruang fisikal pengguna
Hasil :

Konsep tata massa bangunan yang direncanakan adalah massa yang disusun secara cluster dengan pertimbangan kemudahan untuk menciptakan ruang terbuka seperti taman dan area bermain outdoor yang dapat digunakan sebagai media interaksi antar peserta didik dalam (lihat Gambar 15).

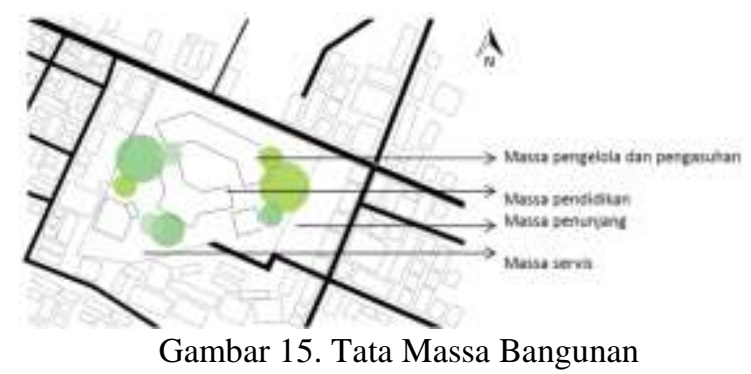

3. Analisis Tampilan Bangunan

Tujuan :

Memperoleh tampilan bangunan yang sesuai dengan fungsi bangunan Pusat Pelayanan Anak Usia Dini yang direncanakan.

Dasar pertimbangan :

a. Tampilan bangunan yang sesuai dengan fungsi dan komunikatif b. Estetika tampilan bangunan yang berbasis anak-anak

c. Persepsi dan proses pengamatan pengguna

Hasil :

Tampilan dinamis diperoleh dengan menggunakan elemen dekoratif berupa bentuk geometri dasar, alphabet, angka dan warna-warna yang cerah (lihat Gambar 16 dan 17).

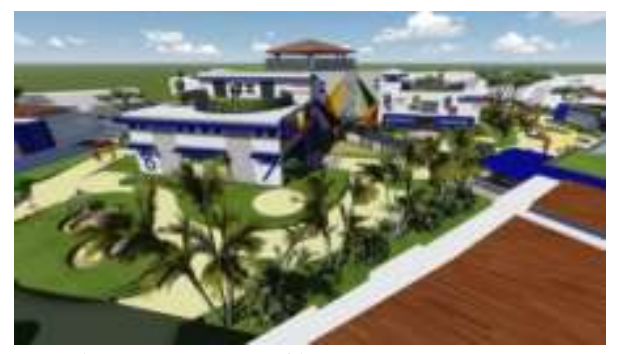

Gambar 16. Tampilan Massa Bangunan Pendidikan

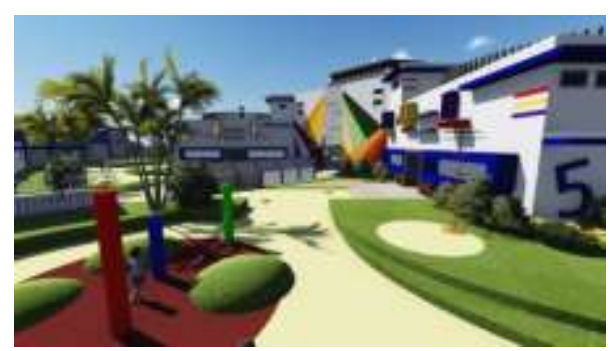

Gambar 17. Detail Tampak Bangunan

E. Analisis Komplementer

1. Analisis Lansekap

Tujuan :

Mendapatkan konsep lansekap yang dibutuhkan pada lingkungan bangunan Pusat Layanan Anak Usia Dini yang direncanakan.

Dasar pertimbangan :

a. Lingkungan pendidikan yang menunjang pembelajaran

b. Kenyamanan pengguna

Hasil :

a. Elemen vegetasi pada obyek rancang bangun (lihat Gambar 18). 


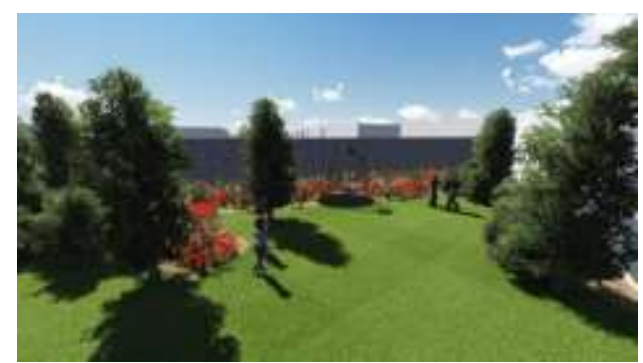

Gambar 18. Elemen Vegetasi

b. Elemen perkerasan

Elemen perkerasan pada area bermain outdoor adalah material jenis karet yang diperuntukkan khusus untuk anak-anak (lihat Gambar 19).

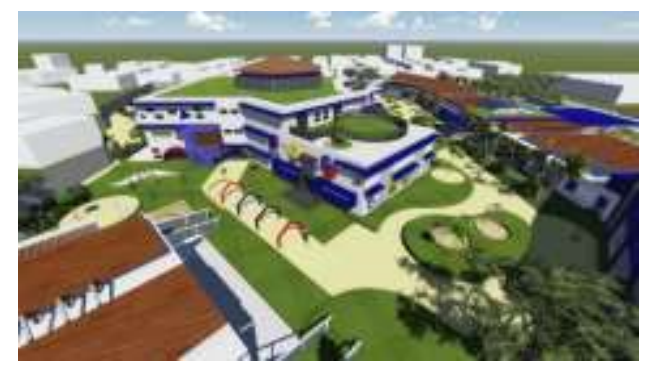

Gambar 19. Elemen Perkerasan Pada Obyek yang Direncanakan

c. Elemen permainan

Peserta didik membutuhkan lingkungan yang kondusif dan suportif untuk mengoptimalkan tumbuh dan kembangnya melalui media permainan yang kreatif dan edukatif (lihat Gambar 20).

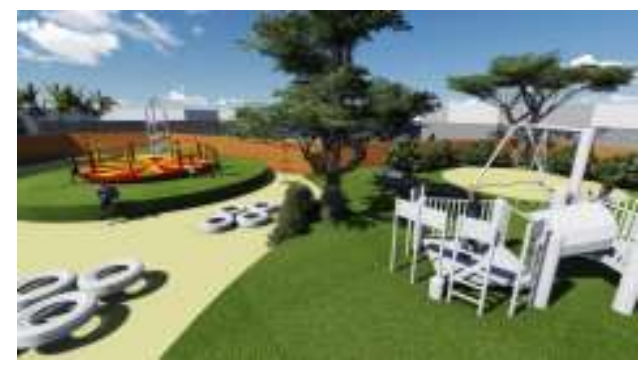

Gambar 20. Elemen Permainan Pada Obyek yang Direncanakan

\section{KESIMPULAN (KONSEP DESAIN)}

Konsep perencanaan dan perancangan Pusat Layanan Anak Usia Dini Terpadu yang menyelenggarakan pendidikan inklusi dengan menerapkan kaidahkaidah Psikologi Arsitektur. Implementasi Psikologi Arsitektur digunakan untuk menunjang keberhasilan pembelajaran inklusi melalui tata massa bangunan yang mudah diakses (lihat Gambar 21 dan 22), ekspresi tampilan ruang yang menarik (lihat Gambar 23, 24 dan 25), serta elemen lansekap berupa vegetasi dan alat-alat permainan yang mampu menunjang tumbuh kembang peserata didik dengan baik (lihat Gambar 26 dan 27).

Dari hasil analisa serta hasil korelasi dari beberapa di atas, maka diperoleh hasil berupa rancangan pusat layanan anak usia dini sebagai berikut :

$\begin{array}{ll}\text { Nama } & : \text { Pusat Layanan Anak } \\ & \text { Usia Dini Terpadu } \\ \text { Lokasi } & : \text { Jalan Kutai Raya } \\ \text { Luas lahan } & : \pm 11.118 \mathrm{~m}^{2} \\ \text { Luas bangunan } & : \pm 9.240,67 \mathrm{~m}^{2} \\ \text { Daya tampung } & : 572 \text { orang } \\ \text { Kegiatan } & : \text { Pendidikan }\end{array}$

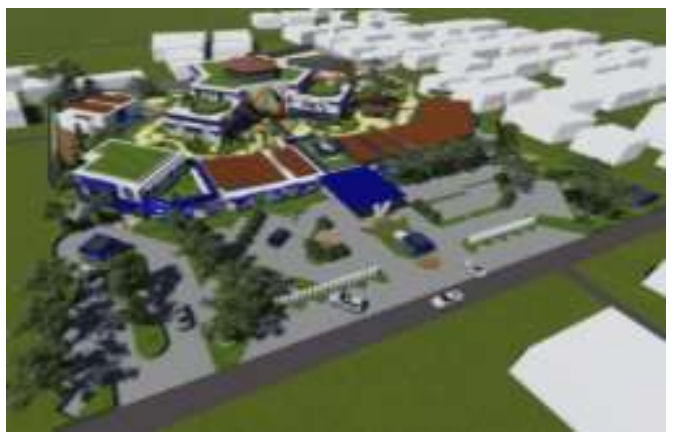

Gambar 21. Perspektif Mata Burung

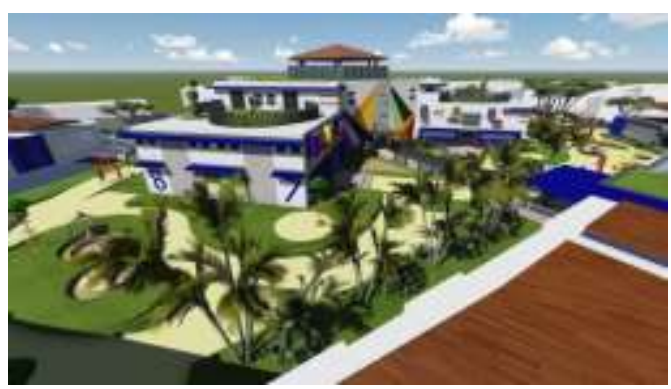

Gambar 22. Perspektif Bangunan Pendidikan

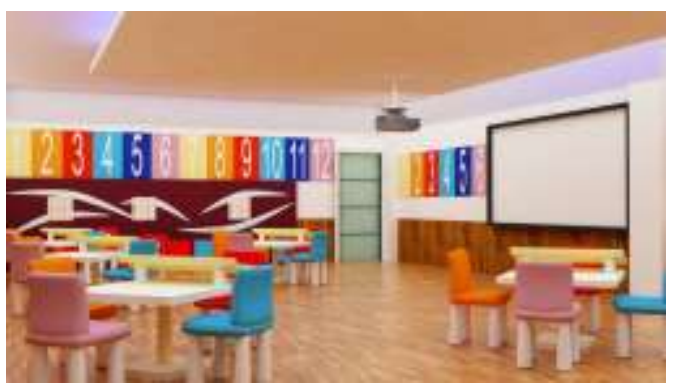

Gambar 23. Interior Ruang Kelas 


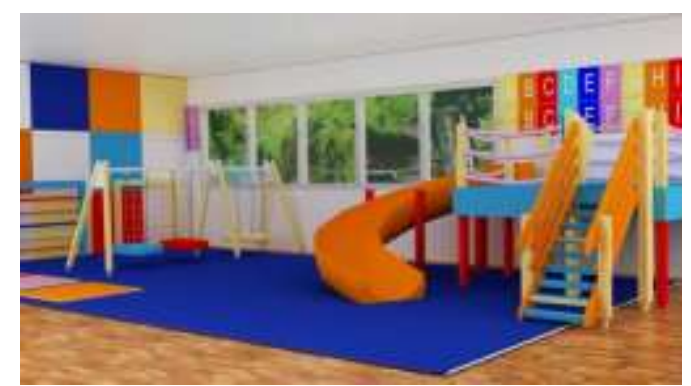

Gambar 24. Interior Ruang Terapi Okupasi

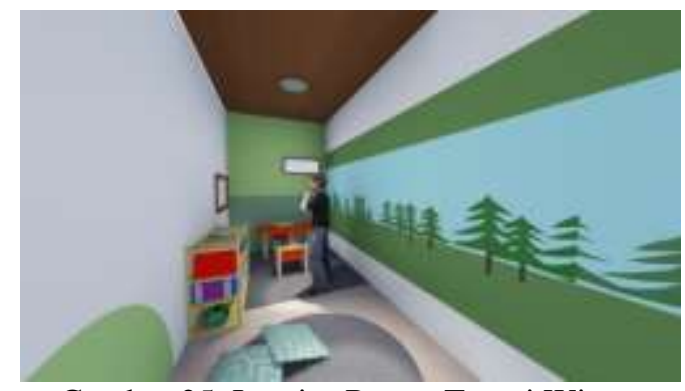

Gambar 25. Interior Ruang Terapi Wicara

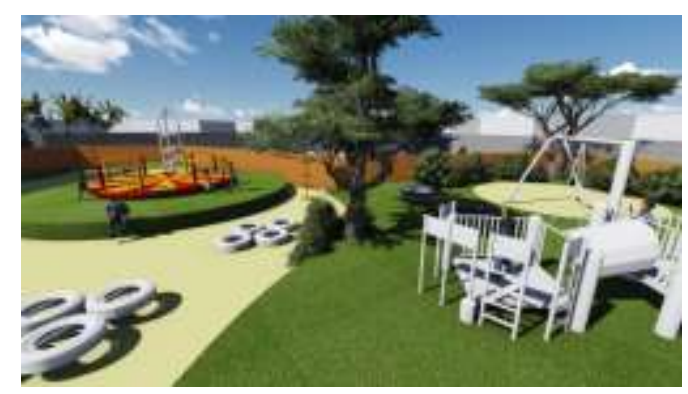

Gambar 26. Arena Bermain Outdoor

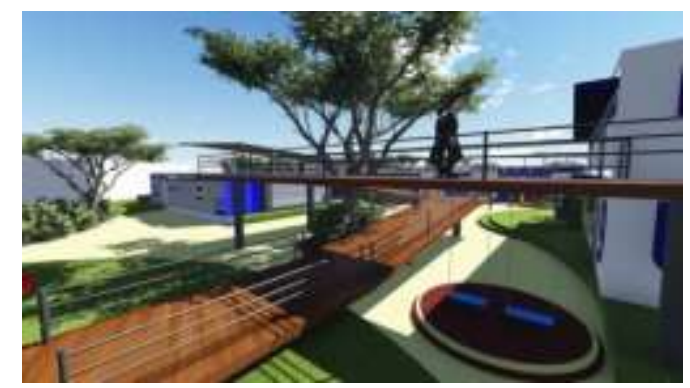

Gambar 27. Area Selasar

\section{REFERENSI}

Direktorat Pendidikan Anak Usia Dini. 2010.

Peraturan Menteri nomor 58 Tahun 2009

Tentang Standar Pendidikan Anak Usia Dini.

Halim, Deddy. 2005. Psikologi Arsitektur. Jakarta: Grasindo.

Neufert, Ernst dan Peter. 2002. Architects'

Data : Third Edition. Jerman:

Blackwells.

RTRW Kota Surakarta Tahun 2012 - 2032.

Sunaryo. 2009. Jurnal: Manajemen

Pendidikan Inklusif. www.edisicetak.joglosemar.co, mengenai jumlah satuan pendidikan inklusi di Surakarta, diakses pada tanggal 10 November 2014. 